\title{
Pink - the colour of hope for uninsured women
}

In an unprecedented breast cancer busting campaign aimed at the medically uninsured, the NGO PinkDrive, tertiary hospitals and clinics in three provinces, plus MediClinic, are temporarily eliminating public sector mammography backlogs, potentially saving thousands of lives.

The typically slow screening of women by overloaded and often understaffed public sector breast clinics does little to increase the cancer detection rate of one in 26 women daily, definitely not improving on the current ratio of one in seven actually dying of the disease. Most women without medical cover present late, often after repeated shunning by busy screening facilities. Far too many women are then diagnosed at an advanced stage of the disease, when little can be done. There are no known studies estimating the ensuing fatalities, but Noelene Kotschan, founder and director of PinkDrive, believes they are alarmingly high. By parking a shocking-pink 10 metre long truck (serving as a mobile mammography unit (MMU)) outside women's health clinics where backlogs are the worst, PinkDrive is hoping to help to reduce the deadly incidence of late presenting breast cancer. From when the charity initiative began in Gauteng in 2010, moving via the Western Cape to KwaZulu-Natal early in October this year, 35000 clinical breast examinations were logged, 4206 mammograms performed and over 45000 women educated on proper breast examination and pro-active self-care.

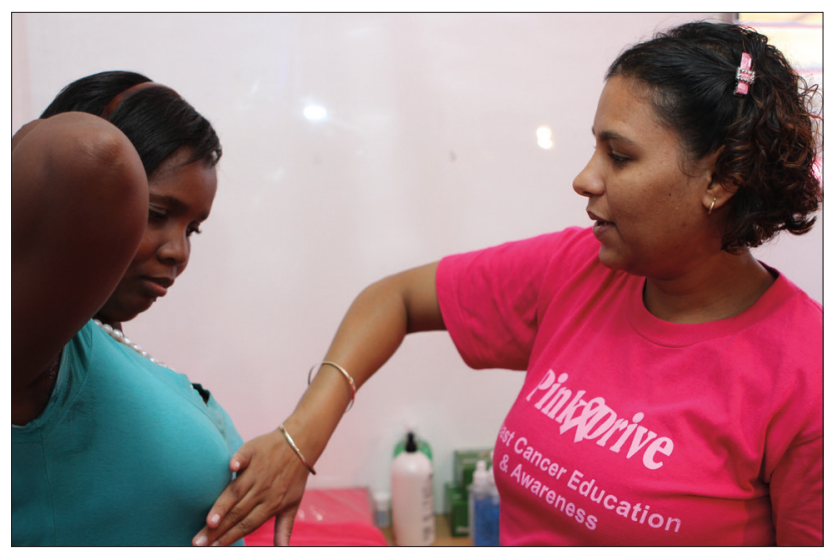

An initial breast exam prior to screening.

\begin{abstract}
Alarming statistics
Breast cancer is the second biggest killer in the world (and on the African continent) and the most common cancer among women. Only $10 \%$ of breast cancer cases are hereditary, further thwarting early detection. By 2050 incidence rates are conditionally predicted to reach six times current levels. Although prevalence is lower in Africa than Europe (41 per 100000 in South Africa versus 89.1 per 100000 in the UK), the overall African mortality rates are among the highest in the world - a direct result of a paucity of services, transport difficulties and the resultant late presentation. More people succumb to all cancers daily world-wide than the sum total of HIV/AIDS, TB and malaria; yet, funding priorities remain with the latter group of diseases.

Kotschan provided another cogent reason for late presentation: 'If you're [a] poor [woman] and fighting to feed your family,
\end{abstract}

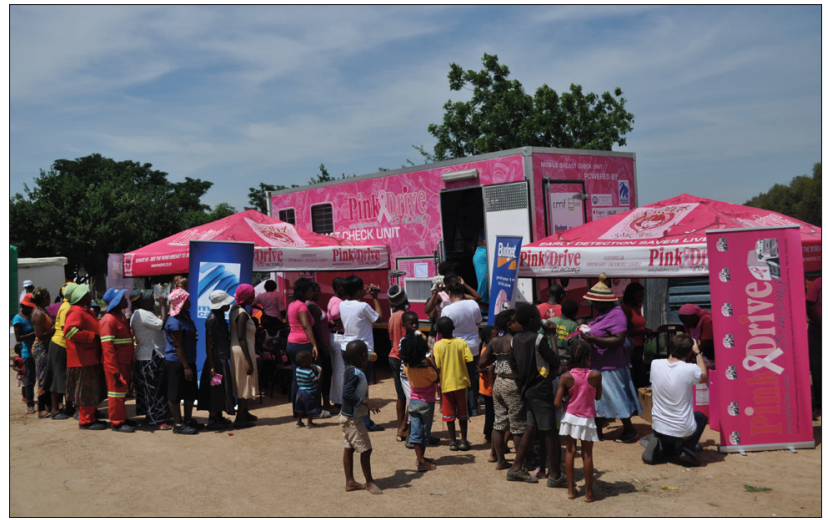

The mobile mammography unit 'in community'.

you'll always put yourself on the back burner,' warning, 'if we don't address this we're just adding to the orphans being left behind'.

Chris Hani-Baragwanath Hospital's Batho Pele Breast Unit (Gauteng) is proving to be a welcome exception to the general rule of struggling to reduce mortality rates through early intervention. They have increased their Stage 1 and 2 breast cancer diagnoses from $29.7 \%$ in $2006 / 2007$ to $54.6 \%$ in $2011 / 2012$ and are identifying on average 250 - 300 new breast cancer patients per year. PinkDrive's MMU spent most of 2010 driving between seven Gauteng hospitals and their feeder clinics, repeating the process at the Western Cape's two major tertiary hospitals last year, generating what Kotschan describes as 'the first true data post 1994' (and eliminating screening backlogs).

\section{Research spin-off}

The data are currently being cleaned and analysed in collaboration with the Batho Pele Breast Unit linked to the Witwatersrand University Health Consortium and the France-based International Agency for Research in Cancer (IARC). For 15 months from February last year to August this year, the MMU worked for three days a week at the Tygerberg Hospital Breast Clinic and feeder hospitals/clinics before moving to Groote Schuur Hospital, where it spent seven consecutive Fridays (Breast Clinic Day). A designated spokesman for Groote Schuur Hospital failed to provide Izindaba with screening backlog (or any associated) data, in spite of repeated requests. From October, PinkDrive began working progressively at Ladysmith, Grey's and Addington hospitals and their associated breast clinics in KwaZulu-Natal. These data will complete a valuable new overall snapshot of trends, incidence and behaviour across the country's three most populous provinces. Speaking in October (World Breast Cancer Awareness month), Dr Sharon Cacala, Head of Surgery at Grey's Hospital in Pietermaritzburg, called for community health workers (an integral part of NHI plans nationally) to conduct breast examinations on patients. She said her experience was that patients usually already presented with breast lesions, making such early community involvement 'absolutely vital'.

The MMU's curiosity-inducing pink livery is enhanced with graphics of bras, panties, lipstick, high heels and handbags and 


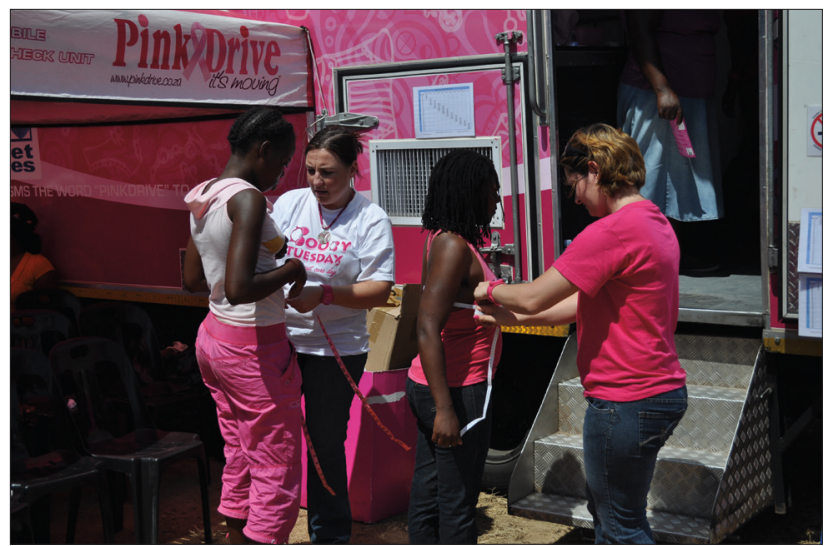

Breast measurement with advice on correct bra-wearing.

staffed by two full-time mammographers (of the 65 certified and registered nationally). The duo is trained to do pre-counselling. PinkDrive also makes a point of helping newly diagnosed women to navigate the public health system, having persuaded a national car rental firm (Budget Car and Van Rental, a Bidvest division) to provide transport for those unable to afford the taxi fares for unexpected and repeated hospital visits. The NGO also supports access to ultrasound, needle biopsies and overall treatment and helps out financially wherever possible. According to Professor Justus Apffelstaedt, Head of the Tygerberg Hospital Breast Clinic, optimal treatment involves getting the best out of each specialty - surgery, radiation, chemotherapy, hormonal therapy and other targeted modalities. He said each worked in different ways but could be 'extra effective' when provided together. Over 100 medications have been approved to treat cancer, with many more being developed.

Kotschan said direct individual financial assistance was budget dependent and based on time-dependent fund-raising. PinkDrive shepherded patients through treatment with 'as much compassion and pragmatism as possible.' 'We try never to leave the patient floundering. If we discover that the waiting time at the clinic is too long, we contact the hospital and expedite the process for her,' she says. Kotschan lost her civil engineer husband Werner to a brain tumour 20 years ago, leaving her to raise two children, then aged 18 months and three years, alone. Shortly after this she lost her father to 'galloping leukaemia', which claimed his life within three weeks of diagnosis. 'I decided I wanted to give back. You get all this lifestyle choice stuff on HIV/AIDS but cancer chooses you,' she says unassumingly of her all-consuming NGO life.

Dr Sharon Cacala, Head of Surgery at Grey's Hospital in Pietermaritzburg, called for community health workers (an integral part of NHI plans nationally) to conduct breast examinations on patients. She said her experience was that patients usually already presented with breast lesions, making such early community involvement 'absolutely vital'.

\section{Radiology Society members pitch in}

MediClinic this year sponsored the MMU's staff, petrol, repairs and maintenance plus private radiology services (the Radiology Society of South Africa encourages members to support

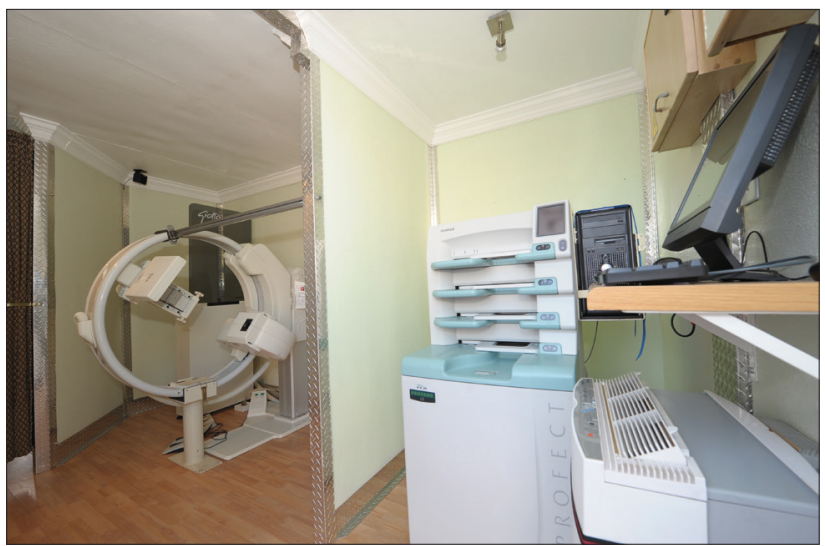

The inside of the mobile mammography unit.

PinkDrive via either pro bono work or a reduced fee) to the tune of R480 000. The vehicle itself (Kotschan has fund-raising plans for another two) was bought with seed capital from the Pfizer Foundation and supplemented by several major corporates in South Africa.

One innovative fund-raising initiative by PinkDrive involves offering the MMU for increasingly popular 'corporate wellness' days. The NGO (registered as a public benefit organisation (PBO)) charges a standard fee and the company identifies medically uninsured women in their employ. 'For every woman screened in the private sector, we can screen two to three in the public for free, Kotschan explains. The Radiological Society identifies willing members closest to the relevant corporate which then delivers batches of 25 screenings for interpretation and reporting. All reports then go to the relevant human resources manager and are distributed accordingly and confidentially. A similar complementary assessment modus operandi is in place in the public sector.

\section{To come: 'More balls than most'}

PinkDrive recently launched its male equivalent of an MMU (prostate and testicular cancer screening) in a campaign to be called 'More balls than most'. These mobile testing units will be colourfully decorated, but with graphics of every kind of sports ball imaginable. Already education and PSA testing have begun in the corporate and school environments.

'Men don't want to talk about such things, so we begin by going into schools, telling those from Grade 8 - 12 what signs to look for and what to do. Both these cancers are starting to affect younger and younger people. We're ring-fencing funds for the larger taxitype vehicles (Toyota Quantum) to help us do this job, she added. Kotschan stressed that awareness and education campaigns, both of which are heavily sponsored and upon which PinkDrive prides itself, were fundamental to successful early intervention and treatment of all types of cancer. Not a single province has contributed financially to PinkDrive's efforts in spite of the NGO having temporarily cleared their mammography backlogs. All pleaded massive budget constraints.

\section{Chris Bateman}

chrisb@hmpg.co.za

$S$ Afr Med J 2012;102(12):902-903.

DOI:10.7196/SAMJ.6466 